\title{
Five-Year Incidence of Amyotrophic Lateral Sclerosis in British Columbia (2010-2015)
}

\author{
Riley Golby, Brigitte Poirier, Marife Fabros, Jacquelyn J. Cragg, Masoud Yousefi, \\ Neil Cashman
}

\begin{abstract}
Background: Amyotrophic lateral sclerosis (ALS) is a fatal degenerative neurological disease with significant effects on quality of life. International studies continue to provide consistent incidence values, though complete case ascertainment remains a challenge. The Canadian population has been understudied, and there are currently no quantitative data on the incidence of ALS in British Columbia (BC). The objectives of this study were to determine the five-year incidence rates of ALS in BC and to characterize the demographic patterns of the disease. Methods: The capture-recapture method was employed to estimate ALS incidence over a five-year period (2010-2015). Two sources were used to identify ALS cases: one database from an ALS medical centre and another from a not-forprofit ALS organization. Results: During this time period, there were 690 incident cases within the two sources. The capture-recapture method estimated 57 unobserved cases, corresponding to a crude five-year incidence rate of 3.29 cases per $100,000\left(C I_{95 \%}=3.05-3.53\right)$. The mean age of diagnosis was $64.6\left(C I_{95 \%}=59.7-69.4\right)$, with $63.5\left(C I_{95 \%}=56.9-70.1\right)$ for men and $65.7\left(C I_{95 \%}=58.6-72.7\right)$ for women. There was a slight male preponderance in incidence, with a 1.05:1 ratio to females. Peak numbers in incidence occurred between the ages of 70 and 79. Conclusions: The incidence of ALS in BC was found to be consistent with international findings though nominally higher than that in other Canadian provinces to date.
\end{abstract}

RÉSUMÉ: Taux d'incidence de la sclérose latérale amyotrophique en Colombie-Britannique de 2010 à 2015. Contexte: La sclérose latérale amyotrophique (SLA) est une maladie neurologique dégénérative qui à terme cause la mort et dont les effets sur la qualité de vie sont notables. Bien que des études internationales continuent de fournir des données cohérentes quant à l'incidence de la SLA, une évaluation complète de cette maladie demeure toujours un défi. À cet égard, la population canadienne n'a pas été suffisamment étudiée ; il n'existe pas non plus, à l'heure actuelle, de données quantitatives en ce qui regarde l'incidence de la SLA en Colombie-Britannique (C.-B.). L'objectif de cette étude a donc été de déterminer sur cinq ans le taux d'incidence de la SLA en C.-B. et de caractériser les aspects démographiques de cette maladie. Méthodes: Nous avons utilisé la méthode de capture-recapture pour estimer l'incidence de la SLA sur une période de cinq ans (2010-2015). Pour ce faire, nous avons exploré deux bases de données, l'une produite par un centre médical spécialisé et l'autre par une organisation sans but lucratif, afin de relever des cas de SLA. Résultats: Au cours de cette période, ces deux bases de données ont révélé 690 cas. La méthode de capture-recapture a aussi estimé que 57 cas n'avaient pas été observés, ce qui correspond, sur cinq ans, à un taux d'incidence brut de 3,29 cas pour 100000 (IC95\% = 3,05 - 3,53). L'âge moyen au moment du diagnostic était de 64,6 ans (IC95\% = 59,7 - 69,4), soit 63,5 ans (IC95\% = 56,9-70,1) pour les hommes et 65,7 ans (IC95\% = 58,6-72,7) pour les femmes. De plus, le taux d'incidence des hommes est apparu légèrement plus élevé, le rapport hommes/femmes étant de 1,05:1. Enfin, soulignons que le plus grand nombre de cas surviennent entre 70 et 79 ans. Conclusions: Il a été constaté que l'incidence de la SLA en C.-B. équivaut à celle observée sur le plan international. À ce jour, elle est aussi nominalement plus élevée que dans les autres provinces canadiennes.

Keywords: ALS, Amyotrophic lateral sclerosis, Incidence, Canada, British Columbia, Epidemiology, Adult, Neurology-Adult doi: $10.1017 / \operatorname{cjn} .2016 .280$

Can J Neurol Sci. 2016; 43: 791-795

\section{INTRODUCTION}

Amyotrophic lateral sclerosis (ALS) is a progressive degenerative motor neuron disease that leads to death in most patients just two to four years after diagnosis. ${ }^{1-9}$ Although there are familial cases of ALS, and established risk factors include age and sex, the disease by and large remains of unknown aetiology. ${ }^{10}$ The Canadian Institute for Health Information studied the expense burden of ALS on the Canadian economy in 2000-2001. ${ }^{11}$ Though morbidity and drug costs were unavailable, they reported

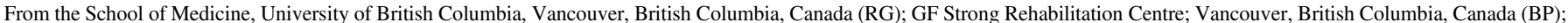

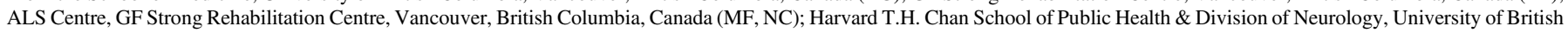

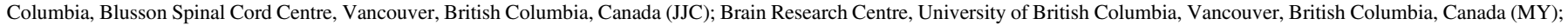

Department of Medicine (Neurology), University of British Columbia, Vancouver, British Columbia, Canada (NC).

Received January 13, 2016. Final Revisions Submitted May 3, 2016. Date of Acceptance May 31, 2016.

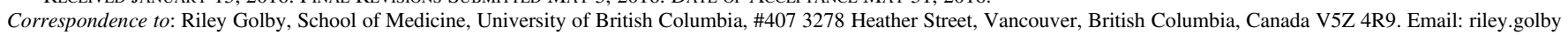

@alumni.ubc.ca. 
the direct cost of ALS on the Canadian economy to be CAD 13.8 million, with mortality costs set at CAD 168.6 million. ${ }^{11}$ Moreover, the direct and indirect costs of previously working ALS patients are approximately CAD 70,000 per individual per year, representing a significant financial burden even in the context of a public healthcare system. ${ }^{12}$

The rapid deterioration and increasing disability associated with ALS makes characterizing the current burden of disease an important benchmark for recognizing changing trends as they arise. Analyzing the geographical distribution of ALS cases by conducting smaller population studies may provide insight into previously unknown environmental risk factors. ${ }^{10}$ Further, characterizing the impact of ALS regionally could improve quality of life for people living with ALS through facilitating more informed resource allocation. For example, provincial not-for-profit societies and outreach programs assist in providing essential assessment, care and equipment to maximize function and comfort throughout the course of the disease. Understanding disease trends could allow them to be more proactive rather than reactive to shifting patient numbers.

Several large international population studies have demonstrated ALS disease incidence rates ranging from 0.3 to 3.6 cases per 100,000 per year. ${ }^{10,13-17}$ This broad range may represent true variation among populations, though it has been suggested that differing methodologies for case collection and inclusion as well as under-ascertainment of cases may also be contributory. ${ }^{9}$ The demographics of this relatively rare disease have not been well characterized in Canada. ${ }^{18}$ Wolfson and colleagues $(2009)^{18}$ systematically reviewed the Canadian literature concerning ALS incidence and prevalence and found only six published studies conducted in four provinces from 1974 to 2004, none of which were from British Columbia (BC). They concluded that there are limited data on the frequency of ALS in Canada and recommended that this be an area for future research. ${ }^{18}$

To more effectively understand disease trends, there is a clear need to examine the burden of ALS in BC. The objectives of the present study are therefore: (1) to determine the five-year incidence rates of ALS from 2010 to 2015 in BC and (2) to characterize the demographic patterns of disease in this population.

\section{MeTHODS}

\section{Case Identification and Data Extraction}

This population-based study was performed in British Columbia, Canada-a province with a well-defined area of $922,509 \mathrm{~km}^{2}$ and population of 4,400,057, as per the 2011 census (see Figure 1). ${ }^{19}$ Healthcare in BC is publicly funded and is divided into five health authorities that serve the geographic regions of the province, with an additional First Nations Health Authority recently implemented. ${ }^{20}$ Ethics approval for our study was obtained from the University of British Columbia Clinical Research Ethics Board and the Vancouver Coastal Health Research Authority.

The study examined incident cases identified from January 1, 2010, through to December 31, 2014. Its design included the use of capture-recapture methodology to assist in more complete case ascertainment. $^{21,22}$ This collection method allows for estimations of unobserved cases when two or more sources are used. ${ }^{21,22}$ To identify incident cases of ALS in our study, two sources were utilized: an ALS clinic patient database from the GF Strong Rehabilitation Centre and the ALS Society of BC patient database.

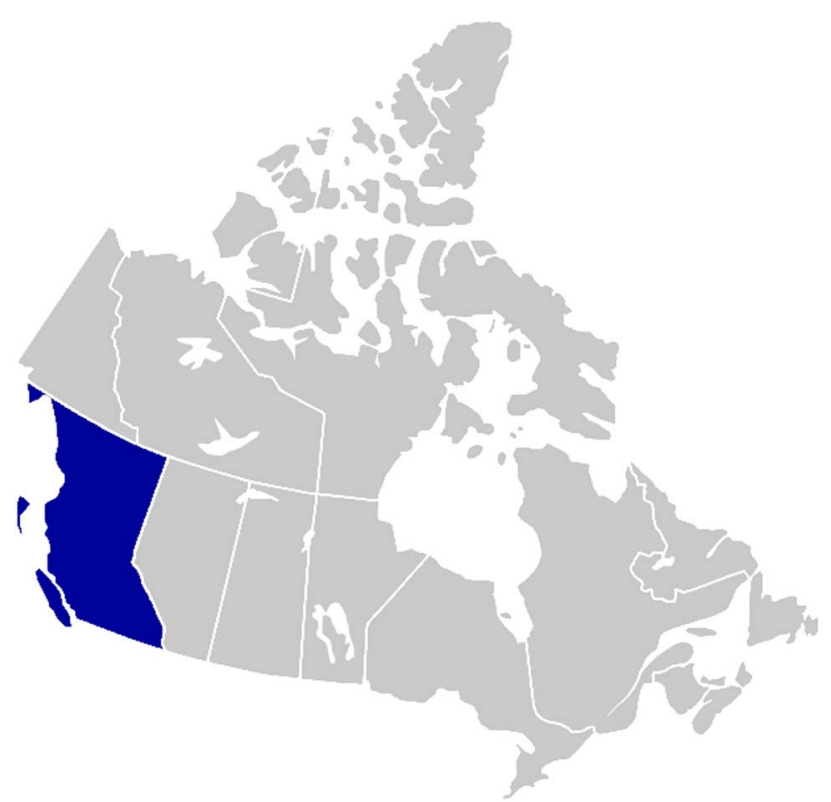

Figure 1: Map of British Columbia, a province of Canada with a land mass of $922,509 \mathrm{~km}^{2}$ and a population of 4,400,057 as of the 2011 National Census. (Source: "Canada Blank Map - Wikimedia Commons." 2016. Originally created by user Lokal_Profil with subsequent modification by Paul Robinson and later Riley Golby. Available at: https:// commons.wikimedia.org/wiki/File:Canada_blank_map.svg.)

The GF Strong Rehabilitation Centre in Vancouver is the largest rehabilitation centre in $\mathrm{BC} .{ }^{24}$ The ALS Centre within this facility is comprised of a multidisciplinary healthcare professional team that provides outpatient assessment, intervention, consultation and educational services. ${ }^{25}$ All patients with a neurologist-confirmed diagnosis of ALS can utilize these services and are registered in a database. These data are maintained throughout the course of their illness.

The ALS Society of BC is a not-for-profit organization that assists people with ALS through quality-of-life support, sponsoring research efforts and increasing public awareness and understanding of ALS. ${ }^{26}$ Services such as an equipment loan program are provided throughout the progression of disease to individuals with a neurologistconfirmed diagnosis of ALS. The database contains up-to-date information regarding people with ALS that have used or are currently using their services. Extracted data from each source included date of diagnosis, age at diagnosis, sex and date of death.

Incident cases were totalled from each source, and the number of unobserved cases was estimated by assessing the degree of overlap between the two sources. Specifically, the Chapman ${ }^{23}$ formula was employed to estimate total patients inclusive of the unobserved cases. Several studies have employed and endorsed this method as a useful tool in more accurate case ascertainment for the ALS population. ${ }^{21,22}$

\section{Inclusion and Exclusion Criteria}

All patients diagnosed with probable or definitive ALS by a neurologist using the El Escorial criteria ${ }^{27}$ during the observation window were included in our study. Suspected and possible cases were not included in collection databases and were therefore excluded. Patients with primary lateral sclerosis were excluded due to inconsistent collection between the two primary sources used. 


\section{Statistical Analysis}

Crude incidence rates were calculated based on the capturerecapture total case estimates per 100,000 individuals in the total British Columbia population. Namely, total crude incident cases along with those stratified by age, sex and year, were summed and divided over the denominator population for each corresponding population groups at large. These figures were then related per 100,000 individuals for comparability. The denominator population values were drawn from Statistics Canada census values within each of the particular intervals examined. ${ }^{28}$ The $95 \%$ confidence intervals $\left(\mathrm{CI}_{95 \%}\right)$ for all incidence rates were derived using the normal approximation.

\section{RESULTS}

From January 1, 2010, through December 31, 2014, there were 690 incident cases captured in the two sources. There were 388 patients identified by both sources. Source one (GF Strong ALS Centre) contained 129 unique cases and source two (ALS Society of BC) 173 unique cases. There were 57 unobserved incident cases estimated by the capture-recapture method, resulting in an estimated total of 747 patients over five years. This produced a crude incidence rate of 3.29 cases per 100,000 $\left(C_{95 \%}=3.05-3.53\right)$. When examining each year individually, the peak incidence occurred during 2013, with a crude capture-recapture rate of 3.77 per 100,000 $\left(C I_{95 \%}=3.20-4.33\right)$. In contrast, the lowest incidence was during 2010 at 2.90 per $100,000\left(C I_{95 \%}=2.40-3.40\right)$. There were slightly more male cases $(51 \%)$ during the five-year study period, with rates at 3.38 per $100,000\left(C_{95 \%}=3.04-3.72\right)$ for men and 3.20 per $100,000 \quad\left(C_{95 \%}=2.87-3.53\right)$ for women. This produced a male-to-female crude incidence ratio of 1.05:1. More detailed results are provided in Table 1 and the Supplemental Data.

Among the various age ranges studied, the highest rate of incidence by age occurred within the 70-79 age group at 13.96 per $100,000\left(C I_{95 \%}=12.07-15.86\right)$. Again, this peaked in 2013 at 17.72 per $100,000\left(C I_{95 \%}=13.02-22.42\right)$. The mean age of diagnosis among all cases was $64.6\left(C I_{95 \%}=59.7-69.4\right)$, with men at $63.5\left(C_{95 \%}=56.9-70.1\right)$ and women at $65.7\left(C_{95 \%}=58.6-\right.$ 72.7) years. More detailed results are provided in Table 2, Figures 1 and 2, and the Supplemental Data.

\section{Discussion}

The present study using the capture-recapture method reports on the incidence of ALS in British Columbia, Canada. Specifically, ALS incidence was found to be 3.29 (3.05-3.53) cases per 100,000 per year. Internationally, large studies have shown rates of 0.3 to 3.6 cases per 100,000 . This number fits within this range, indicating that it is representative of the general population.

Table 1: Five-Year Capture-Recapture Estimated Incidence Rates

\begin{tabular}{l|c|c|c}
\hline $\mathbf{2 0 1 0 - 2 0 1 5}$ & Cases & Population & $\begin{array}{c}\text { Crude incidence rate } \\
\left(\boldsymbol{C I}_{\mathbf{9 5} \%}\right) \text { per 100,000 }\end{array}$ \\
\hline Cumulative & 747 & $22,718,824$ & $3.29(3.05-3.53)$ \\
\hline Male & 382 & $11,290,679$ & $3.38(3.04-3.72)$ \\
\hline Female & 365 & $11,428,145$ & $3.20(3.16-3.85)$ \\
\hline
\end{tabular}

Table 2: Five-Year Capture-Recapture Estimated Incidence by Age Groups

\begin{tabular}{l|c|c|c}
\hline Age range & Cases & Population & $\begin{array}{c}\text { Crude incidence rate } \\
\left(\boldsymbol{C I}_{\mathbf{9 5} \%}\right) \text { per 100,000 }\end{array}$ \\
\hline $0-29$ & 5 & $7,927,731$ & $0.06(0.01-0.12)$ \\
\hline $30-39$ & 11 & $3,009,603$ & $0.35(0.14-0.56)$ \\
\hline $40-49$ & 39 & $3,314,810$ & $1.19(0.82-1.56)$ \\
\hline $50-59$ & 168 & $3,411,620$ & $4.91(4.17-5.66)$ \\
\hline $60-69$ & 247 & $2,590,149$ & $9.55(8.36-10.74)$ \\
\hline $70-79$ & 208 & $1,490,990$ & $13.96(12.07-15.86)$ \\
\hline$\geq 80$ & 70 & 973,921 & $7.21(5.53-8.90)$ \\
\hline
\end{tabular}

Despite this, the incidence rate does appear nominally higher than those reported in all other Canadian studies, where incidence ranges from 1.63 to 3.01 per 100,000 inhabitants in Ontario and Quebec, respectively. ${ }^{18}$ There are several reasons why this may be the case. As the recent Canadian systematic review ${ }^{18}$ noted, there is a dearth of evidence with respect to ALS epidemiology in Canada. To this end, many populations across Canada remain unstudied, opening the possibility that several regions in Canada may actually have a far greater burden of disease than expected. At the present time, more Canadian provinces remain unstudied than those with reported data. The heterogeneity among Canadian provinces both in geography and demographics creates a potential for valuable studies to examine possible unique regional risk factors. With the advent of new ALS registries, ${ }^{29}$ it is likely that understanding of disease burden in Canada will continue to be fortified.

Another possibility for why BC numbers are more substantial could merely be reflective of the window of time in which they were measured. The closest window of Canadian data studied comes from a Quebec regional study ${ }^{30}$ where 2005-2009 disease incidence was captured. They found a rate of 3.01 per 100,000 per year for the five-year window-second only in quantity and timing to the $\mathrm{BC}$ data ${ }^{30}$ It could be that more recent measurements of ALS numbers reflect a time of greater incidence or better case ascertainment. In the

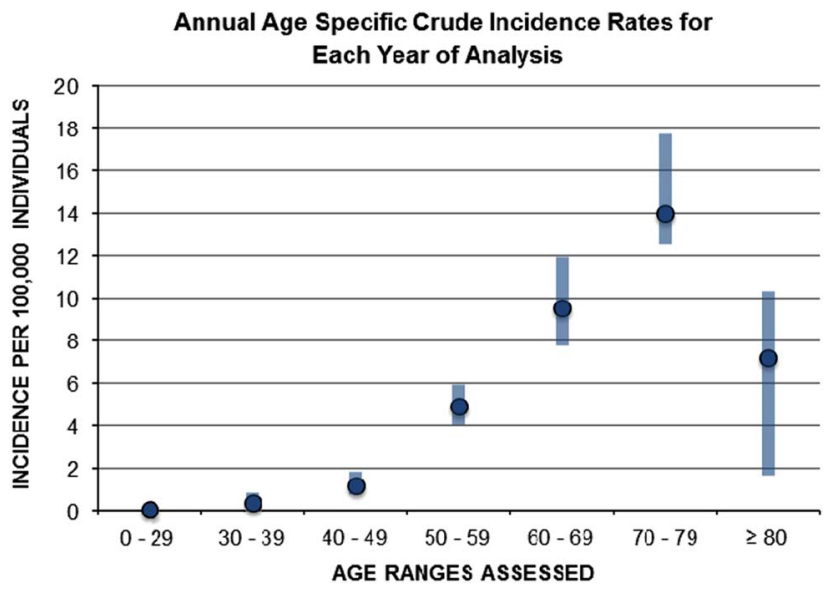

Figure 2: Crude incidence rates per 100,000 individuals specific to age. This graph demonstrates all five years (2010-2015) individually shown as a range of incidence values for each age category. The cumulative five-year incidence value is highlighted as a point within the range. 
present study, as highlighted in the Supplemental Data, incidence increases each year from 2010 through to 2014 and then decreases during 2014. This is likely a function of observation time in the registry, but it could represent a genuine pattern of increase in British Columbia. Again, the presence of a dynamic national registry may assist in more accurately capturing trends in disease burden for Canada. If it can engage the Canadian ALS population effectively, no doubt it will be a less cumbersome way of noting shifts in incidence, rather than serial provincial studies.

Indeed, yet another possibility is that BC could actually have a truly greater incidence based on inherent provincial qualitiesunascertained unifying risk factors for this disease. There are several factors associated with ALS risk-including age, male sex and family history of ALS - along with others currently being studied. ${ }^{31}$ As more risk factors become defined, future studies in BC could focus on the traits of this population in relation to disease burden, especially if $\mathrm{BC}$ data consistently remain uniquely elevated.

It was not the goal of our study to consider what these might include, but one area of particular interest for future work may be to examine the impact of immigration on disease trends. In British Columbia, the region of birth for immigrants has shifted dramatically over time. Most notably, immigrants from the Asian continent now constitute the majority of newcomers to Canada, when prior to 1971 they amounted to less than $10 \% .^{32}$ Further, Vancouver received $13.3 \%$ of all new immigrants to Canada in 2011 alone. $^{32}$ Within the current ALS data sources in British Columbia, information on patient ethnicity is not available; however, differences in disease incidence among various ethnic mosaics will be an important consideration for future provincial studies.

Our findings also indicate a very slight male preponderance, with a ratio of $1.05: 1$, as also noted in previous studies. ${ }^{10,32}$ One possible explanation for this minor difference is that women may be less exposed to some environmental risk factors-such as trauma, physical activity, smoking, occupational exposure and others currently being investigated for their link to ALS. ${ }^{31}$ Distinctly or concurrently, this difference could also reflect underascertainment of ALS among women, though this requires more investigation to discern. Some studies ${ }^{3,6,33}$ have found a more significant difference between male and female case numbers, so it is possible that the similar rates noted in our study reflects improved diagnostic capture of female patients.

We also observed increasing cases with age-specific incidence, peaking between 70 and 79 years of age, with a mean age of diagnosis at $64.6\left(C_{95 \%}=59.7-69.4\right)$ years. Most international studies $^{8,10,15,28}$ have a peak incidence within a similar age range, with reduced rates at ages beyond 80 years. It has been suggested that this late peaking pattern reflects lifelong exposures to risk factors or agents that create a window of maximal susceptibility to ALS. ${ }^{9}$ This maximum susceptibility appears to either taper off in the oldest age groups or reflects under-ascertainment in this age range. Understandably, the diagnosis of ALS in the elderly may be more difficult because of the presence of comorbidities, particularly with diseases affecting the musculoskeletal and nervous systems.

\section{Study Strengths And Limitations}

Our study was conducted in a well-defined geographical region, using two patient registries as the source of cases, as well as the El Escorial criteria for ALS diagnosis. Some of the limitations of this study, however, include the inability to achieve complete case ascertainment. Capture-recapture analysis was utilized for each age category and sex, as well as for the total population. This methodology is gaining momentum as an accurate way to achieve more complete case ascertainment in a setting of individually incomplete sources. Ideally, however, a single registry or centralized government tracking system would account for all diagnosed cases in the province. Encouragingly, a registry of this nature has been developed for use in Canada. ${ }^{29}$

\section{CONCLUSIONS}

Using the capture-recapture method, in the present study we report the incidence of ALS in British Columbia, Canada, as 3.29 cases per $100,000\left(C I_{95 \%}=3.05-3.53\right)$. Ours is the first study dedicated to incidence in the BC population and thus fulfils the role as an important regional benchmark for future studies of ALS interventions and epidemiology.

\section{ACKNOWLEDGMENTS}

Many thanks to the Centre for Health Evaluation and Outcome Services (CHEOS) within the Providence Health Care Research Institute (Vancouver, BC), and in particular Joseph Puyat for his assistance with study design and implementation; to Eva Cham for her contributions in forming and maintaining ALS patient data within the ALS centre at the GF Strong Rehabilitation Centre; to Drs. Gary Poole and Nicole Fairbrother within the UBC Faculty of Medicine for their ongoing support of facilitating research efforts among medical undergraduates; and to Wendy Toyer and the rest of the ALS Society of British Columbia for their relentless support of the ALS community and maintenance of the ALS Society patient database. Finally, we acknowledge that JJC is an ALS Canada Tim E. Noël Postdoctoral Fellow and is supported by the Michael Smith Foundation for Health Research (MSFHR).

\section{FUNDING}

This work was unfunded.

\section{Disclosures}

Riley Golby, Brigitte Poirier, Marife Fabros, Jacquelyn J. Cragg, Masoud Yousefi and Neil Cashman hereby declare that they have nothing to disclose.

\section{Statement of Authorship}

$\mathrm{RG}$ and NC were responsible for research conception and design. $\mathrm{RG}, \mathrm{BP}, \mathrm{MF}, \mathrm{MY}$ and NC were involved in implementation of this research project. RG and MY undertook the analysis of data and contributed to the methods section of the draft manuscript. $\mathrm{RG}$, JC and NC contributed to interpretation of the research findings. RG developed the initial publication outline. All of the contributors co-authored multiple drafts of the manuscript. All made critical revisions for important intellectual content and approved the final manuscript.

\section{Supplementary Material}

For supplementary material/s referred to in this article, please visit http://dx.doi.org/doi:10.1017/cjn.2016.280 


\section{REFERENCES}

1. Logroscino G, Traynor BJ, Hardiman $\mathrm{O}$, Chiò A, Couratier $\mathrm{P}$, Mitchell JD, et al. Descriptive epidemiology of amyotrophic lateral sclerosis: new evidence and unsolved issues. J Neurol Neurosurg Psychiatry. 2008;79(1):6-11.

2. Sorenson EJ, Stalker AP, Kurland LT, Windebank AJ. Amyotrophic lateral sclerosis in Olmsted County, Minnesota, 1925 to 1998. Neurology. 2002;59:280-2.

3. Huisman M, de Jong S, van Doormaal P, Weinreich SS, Schelhaas HJ, van der Kooi AJ, et al. Population-based epidemiology of amyotrophic lateral sclerosis using capture-recapture methodology. J Neurol Neurosurg Psychiatry. 2011;82(10):1165-70. Epub ahead of print May 27.

4. Mortara P, Chiò A, Rosso M, Leone M, Schiffer D. Motor neuron disease in the province of Turin, Italy, 1966-1980. J Neurol Sci. 1984;66(2-3):165-73.

5. Lee C, Chiu Y, Wang K, Hwang CS, Lin KH, Lee IT, et al. Riluzole and prognostic factors in amyotrophic lateral sclerosis long-term and short-term survival: a population-based study of 1149 cases in Taiwan. J Epidemiol. 2013;23:35-40. Epub ahead of print Oct 27, 2012.

6. Pugliatti M, Parish L, Cossu P, Leoni S, Ticca A, Saddi MV, et al. Amyotrophic lateral sclerosis in Sardinia, insular Italy, 1995-2009. J Neurol. 2013;260(2):572-9. Epub ahead of print Sep 30, 2012.

7. Byrne S, Elamin M, Bede P, Shatunov A, Walsh C, Corr B, et al. Cognitive and clinical characteristics of patients with amyotrophic lateral sclerosis carrying a C9orf72 repeat expansion: a populationbased cohort study. Lancet Neurol. 2012;11(3):232-40. Epub ahead of print Feb 3. Erratum in: Lancet Neurol. 2012;11(5):388.

8. Chiò A, Logroscino G, Hardiman O, Swingler R, Mitchell D, Beghi E, et al. Prognostic factors in ALS: a critical review. Amyotroph Lateral Scler. 2009;10(5-6):310-23.

9. Abhinav K, Stanton B, Johnston C, Hardstaff J, Orrell RW, Howard $\mathrm{R}$, et al. Amyotrophic lateral sclerosis in South-East England: a population-based study. Neuroepidemiology. 2007;29(1-2):44-8. Epub ahead of print Sep 24

10. Chiò A, Logroscino G, Traynor B, Collins J, Simeone JC, Goldstein LA, et al. Global epidemiology of amyotrophic lateral sclerosis: a systematic review of the published literature. Neuroepidemiology. 2013;41(2):118-30. Epub ahead of print Jul 11.

11. Canadian Institute for Health Information. The Burden of Neurological Diseases, Disorders, and Injuries in Canada. Ottawa: Canadian Institute for Health Information; 2007. Available at: http://www.cpa.ca/cpasite/UserFiles/Documents/Practice_Page/ Burden_neuro_diseases_en.pdf.

12. Gladman M, Dharamshi C, Zinman L. Economic burden of amyotrophic lateral sclerosis: a Canadian study of out-of-pocket expenses. Amyotroph Lateral Scler Frontotemporal Degener, 2014;15:426-32; Epub ahead of print Jul 15.

13. Traynor B, Codd M, Corr B, Forde C, Frost E, Hardiman O. Incidence and prevalence of ALS in Ireland, 1995-1997: a population-based study. Neurology. 1999;52(3):504-9.

14. Logroscino G, Beghi E, Zoccolella S, Palagano R, Fraddosio A, Simone IL, et al. Incidence of amyotrophic lateral sclerosis in southern Italy: a population based study. J Neurol Neurosurg Psychiatry. 2005;76(8):1094-8.

15. Beghi E, Millul A, Micheli A, Vitelli E, Logroscino G. Incidence of ALS in Lombardy, Italy. Neurology. 2007;68(2):141-5.

16. O'Toole O, Traynor B, Brennan P, Sheehan C, Frost E, Corr B, et al. Epidemiology and clinical features of amyotrophic lateral sclerosis in Ireland between 1995 and 2004. J Neurol Neurosurg Psychiatry. 2008;79(1):30-2. Epub ahead of print Jul 18.

17. Sejvar J, Holman R, Bresee J, Kochanek K, Schonberger L. Amyotrophic lateral sclerosis mortality in the United States, 1979-2001. Neuroepidemiology. 2005;25(3):144-52.

18. Wolfson C, Kilborn S, Oskoui M, Genge A. Incidence and prevalence of amyotrophic lateral sclerosis in Canada: a systematic review of the literature. Neuroepidemiology. 2009; 33(2):79-88. Epub ahead of print May 30.

19. Statistics Canada. Census Profile. Ottawa: Statistics Canada; 2012. Available at: http://www12.statcan.gc.ca/census-recensement/ 2011/dp-pd/prof/index.cfm?Lang=E.

20. Province of British Columbia. Health Authorities; 2015. Available at: http://www2.gov.bc.ca/gov/content/health/about-bc-s-healthcare-system/partners/health-authorities.

21. Donaghy C, Clarke J, Patterson C, Kee F, Hardiman O, Patterson V. The epidemiology of motor neuron disease in Northern Ireland using capture-recapture methodology. Amyotroph Lateral Scler. 2010;11(4):374-8

22. Huisman M, de Jong S, van Doormaal P, Weinreich SS, Schelhaas HJ, van der Kooi AJ, et al. Population based epidemiology of amyotrophic lateral sclerosis using capture-recapture methodology. J Neurol Neurosurg Psychiatry. 2011;82(10):1165-70. Epub ahead of print May 27.

23. Chapman CJ. Some properties of the hypergeometric distribution with applications to zoological censuses. Univ Calif Pub Stat. 1951;1:131-60.

24. Vancouver Coastal Health. GF Strong Rehabilitation Centre; 2015. Available at: http://www.vch.ca/locations-and-services/findlocations/find-locations?site id=73.

25. Vancouver Coastal Health. Amyotrophic Lateral Sclerosis CentreGF Strong Rehabilitation Centre; 2015. Available at: http://www. vch.ca/locations-and-services/find-health-services/?program_id $=952$.

26. Amyotrophic Lateral Sclerosis Society of British Columbia. For Care and to Support a Cure for ALS; 2015. Available at: http://www. alsbc.ca/.

27. Brooks B. El Escorial World Federation of Neurology criteria for the diagnosis of amyotrophic lateral sclerosis. J Neurol Sci. 1994;124(Suppl):96-107.

28. BC Stats. Population Estimates, British Columbia and Sub-Provincial; 2016. Available at: http://www.bcstats.gov.bc.ca/Statis ticsBySubject/Demography/PopulationEstimates.aspx.

29. Korngut L, Genge A, Johnston M, Benstead T, Bourque P, Briemberg $\mathrm{H}$, et al. Establishing a Canadian registry of patients with amyotrophic lateral sclerosis. Can J Neurol Sci. 2013;40(01): 29-35.

30. Lareau-Trudel É, Fortin É, Gauthier M, Lavoie S, Morissette É, Mathieu J. Epidemiological surveillance of amyotrophic lateral sclerosis in Saguenay region. Can J Neurol Sci. 2013;40(05): 705-9.

31. Ingre C, Roos PM, Piehl F, Kamel F, Fang F. Risk factors for amyotrophic lateral sclerosis. Clin Epidemiol. 2015;7: 181-93.

32. Statistics Canada. Immigration and Ethnocultural Diversity in Canada; 2015. Available at: https://www12.statcan.gc.ca/nhsenm/2011/as-sa/99-010-x/99-010-x2011001-eng.cfm.

33. Logroscino G, Traynor BJ, Hardiman O, Chiò A, Mitchell D, Swingler RJ, et al. Incidence of amyotrophic lateral sclerosis in Europe. J Neurol Neurosurg Psychiatry. 2010;81(4):385-90. Epub ahead of print Aug 25, 2009. 